\title{
Yanıt Yüzey Metodolojisi Kullanılarak 1-Propanol/Benzin Yakıt Karışımlarının Egzoz Emisyonlarına Etkisinin Araştırılması
}

\author{
Mehmet Selman Gokmen ${ }^{1 *}$, Ibrahim Dogan ${ }^{2}$, Hasan Aydogan ${ }^{3}$ \\ 1*Necmettin Erbakan Üniversitesi, Seydişehir MYO, Mot. Ar. ve Ulaş. Tek. Bölümü, Konya, Türkiye, (ORCID: 0000-0001-5943-7504), msgokmen@erbakan.edu.tr \\ ${ }^{2}$ Selçuk Üniversitesi, Fen Bilimleri Enstitüsü, Makine Mühendisliği Bölümü, Konya, Türkiye (ORCID: 0000-0002-1448-8911), ibrahimdogan0594@gmail.com \\ ${ }^{3}$ Selçuk Üniversitesi, Teknoloji Fakültesi, Makine Mühendisliği Bölümü, Konya, Türkiye (ORCID: 0000-0003-1404-6352), haydogan@selcuk.edu.tr
}

(2nd International Conference on Access to Recent Advances in Engineering and Digitalization (ARACONF)-10-12 March 2021)

(DOI: 10.31590 /ejosat.898563)

ATIF/REFERENCE: Gokmen, M. S., Dogan, I. \& Aydogan, H. (2021). Yanıt Yüzey Metodolojisi Kullanılarak 1-Propanol/Benzin Yakıt Karışımlarının Egzoz Emisyonlarına Etkisinin Araştırılması. Avrupa Bilim ve Teknoloji Dergisi, (24), 67-74

$\ddot{O} z$

Bu çalışmada, 1-Propanolün benzin ile karıştırılması ile elde edilen yakıt karışımlarının egzoz emisyon değerlerine etkisi yanıt yüzey metodolojisi ile deneysel olarak incelenmiştir. Yanıt Yüzey Metodolojisi (YYM) için giriş faktörleri 1-Propanol oranı ile Motor devri ve yanıt değerleri ise karbonmonoksit $(\mathrm{CO})$, karbon dioksit $\left(\mathrm{CO}_{2}\right)$, hidrokarbon $(\mathrm{HC})$, Azot Oksit $(\mathrm{NO})$ ve Oksijen $\left(\mathrm{O}_{2}\right)$ emisyonları olarak belirlenmiştir. Oluşturulan YYM tasarımında 3 Seviye Faktöriyel Tasarım (3SFT) tekniği kullanılarak deneyler planlanmıştır. Deney planları sonucunda motor devri 1500, 2500 ve $3500 \mathrm{~d} / \mathrm{dk}$ ayrıca 1 -propanol oranı ise \%5, \%10 ve \%15 (\% hacim) olarak belirlenerek 3 farklı karışım ve \%100 Benzin için toplam 12 farklı ölçüm gerçekleştirilmiş ve sonuçlar istatistiksel olarak değerlendirilmiştir. Elde edilen sonuçlara göre $\mathrm{CO}, \mathrm{CO}_{2}, \mathrm{HC}, \mathrm{O}_{2}$ ve $\mathrm{NO}$ emisyonları için optimum değerleri sırasıyla \%98.58, \%98.88, $\% 99.03$, \%99.33 ve \%98.51 doğrulukta \% 0.292, \%7.07, 45.55 ppm, \%7.49 ve 1298.42 ppm olarak tahmin edilmiştir. Sonuçların istatistiksel olarak önemli olması, YYM kullanılarak benzin karışımlarının emisyon değerleri üzerindeki etkilerinin daha az test sayısı ile verimli bir şekilde incelenebildiğini göstermektedir. Çalışma sonuçlarına göre 1-Propanol karışımları tüm devirlerde $\mathrm{CO}_{2}, \mathrm{HC}, \mathrm{O}_{2}$, NO emisyonlarını azaltmıştır fakat CO emisyonu için en düşük değerler \%100 benzin ile yapılan testlerde elde edilmiştir.

Anahtar Kelimeler: 1-Propanol, Benzin, Egzoz Emisyon, Deney Tasarımı, Yanıt Yüzey Metodolojisi, Optimizasyon.

\section{Investigation of the Effect of 1-Propanol / Gasoline Fuel Blends on Exhaust Emissions Using Response Surface Methodology}

\begin{abstract}
In this study, the effect of 1-Propanol / Gasoline fuel mixtures on exhaust emission values has been experimentally investigated using response surface methodology. The input factors for Response Surface Methodology (YYM) are 1-Propanol ratio and Engine speed and response values are determined as carbon monoxide $(\mathrm{CO})$, carbon dioxide $\left(\mathrm{CO}_{2}\right)$, hydrocarbon $(\mathrm{HC})$, Nitrogen Oxide (NO) and Oxygen $\left(\mathrm{O}_{2}\right)$ emissions. In the created YYM design, experiments were planned by using 3 Level Factorial Design (3SFT) technique. Engine speed was determined as 1500, 2500 and 3500 (rpm), and 1-propanol ratio was determined as 5\%, 10\% and 15\% (volume \%). A total of 12 different measurements were performed for 3 different mixtures and 100\% Gasoline and the results were evaluated statistically. Optimum values for $\mathrm{CO}, \mathrm{CO}_{2}, \mathrm{HC}, \mathrm{O}_{2}$ and $\mathrm{NO}$ emissions were estimated as $0.292 \%, 7.07 \%, 45.55 \mathrm{ppm}, 7.49 \%$ and $1298.42 \mathrm{ppm}$, respectively. The accuracy rates of the estimates were calculated as $98.58 \%, 98.88 \%, 99.03 \%, 99.33 \%$ and $98.51 \%$ for emission values, respectively. The statistical significance of the results shows that the effects of gasoline mixtures on emission values can be examined efficiently with less number of tests using YYM. According to the results of the study, 1-Propanol mixtures reduced $\mathrm{CO}_{2}, \mathrm{HC}_{2} \mathrm{O}_{2}, \mathrm{NO}$ emissions in all cycles, but the lowest values for CO emission were obtained in tests with $100 \%$ gasoline.
\end{abstract}

Keywords: 1-Propanol, Gasoline, Exhaust Emission, Design of Experiment, Response Surface Methodology, Optimization.

* Sorumlu Yazar: msgokmen@erbakan.edu.tr 


\section{Giriş}

Benzin, ham petrolün rafineride işlenmesi ile elde edilen yapısında aromatik ve parafin bulunduran bir yakıttır (Acaroğlu et al., 2018). Yapısında bulunan parafinler yanıcı özelliklerinden dolayı benzinin ateşleme performansını artırırken vuruntu direncini ise düşürdüğü için benzen ve izoparafinler vuruntu kontrolü sağlamak için rafineride ilave edilmektedir (Jarmon \& Anderson, 2005). Fiziksel ve kimyasal özelliklerinden dolayı iklimsel koşullardan çok etkilenen bir yakıt olmasına rağmen rafineriler kabul edilebilir motor performansı sağlayan, standart ve düşük maliyetli benzin üretimi yapmaktadır. $\mathrm{Bu}$ nedenle gelişmiş ülkeler iklim ve tüketim koşullarını göz önüne alarak kendi iç rafinerilerinde standart benzinin özelliklerini kendi ihtiyaçları doğrultusunda geliştirmektedir (Reif, 2015). Yakıtların sağlaması gereken temel özellikler standartlar ile belirlenmiştir fakat iklimsel ve bölgesel koşullar göz önüne alındığı zaman genellikle farklı katkı maddeleri kullanılarak bir takım özelliklerin geliştirilmesine ihtiyaç duyulmaktadır. Yakıt katkılarının ilavesi ile standart yakıtın sağladığı motor performansının artırılması, zararlı emisyonların azaltılması gibi temel parametrelerin yanı sıra korozif etkilerin önlenmesi, yağlayıcı özelliklerin iyileştirilmesi, yakıt stabilizesinin yükseltilmesi gibi özelliklerinde geliştirilmesi amaçlanmaktadır (Srivastava \& Hancsók, 2014).

Benzin yakıtının oksijen içeriği daha iyi bir yanma ve daha düşük emisyon değerleri sağlaması amacı ile 1-Propanol kullanılarak artırılabilmektedir (Qian et al., 2018). 1-Propanol yapısında üç adet karbon bulundurur ve $\mathrm{CH}_{3} \mathrm{H}_{7} \mathrm{OH}$ formülü ile tanımlanmaktadır (Gawale \& Naga Srinivasulu, 2020). Yapısında bulunan $\mathrm{OH}$ grupları benzinin oksijen içeriğini artırmaktadır (Mourad \& Mahmoud, 2018). Aynı zamanda oktan sayısının yüksek olması ile benzinin vuruntu direncini artırmaktadır. Endüstride çözücü ve buzlanma önleyici olarak yaygın olarak kullanılmakta olan 1-Propanol yakıt sisteminin temizlenmesine katkı sağlamaktadır (Liu et al., 2016). OH grubu metanol ve etanolden farklı olarak zincir sonunda doğrudan karbon'a bağlanmıştır ve yüksek moleküller arası etkileşime sahip olduğu için kaynama noktası benzin, etanol ve metanolden daha yüksektir (Papa, 2000). Ayrıca (Li et al., 2019) tarafından yapılan çalışmada ise 1-Propanolün doğrusal kimyasal zincir yapısından dolay1 laminer alev hızının yüksek olduğu belirtilmiştir. Yüksek laminer alev hızı yanmayı iyileştirdiği için emisyonların indirgenmesine katkı sağlamaktadır.

1920 li yıllarda Sir Ronald A. Fisher' in istatistiksel deney tasarımını geliştirmesi ardından faktöriyel tasarım kavramı ve varyans analizinin gelişimine yaptığı katkılar ile birlikte 1951 yılında Box ve Wilson (Draper, 1992) tarafindan Yanıt Yüzey Metodolojisi geliştirilmiştir. $\mathrm{Bu}$ metodoloji ile birlikte test parametrelerinin ve prosesinin optimizasyonu sağlanmıştır (Montgomery, 2006). YYM son y1llarda içten yanmalı motor testlerinde deneylerin tasarımı, maliyetlerin düşürülmesi ve optimizasyon amacı ile yaygın olarak kullanılmaktadır (Abdalla et al., 2019; Bote et al., 2020; Yusri et al., 2017).

Son yıllarda çevre ve insan sağlığına olumsuz etkileri nedeni ile diesel araçlarının kullanılmasına dünya genelinde sınırlandırmalar getirilmektedir. Yaşanan gelişmeler araştırmacıların ilgisini çekmiş ve benzin yakıtının özelliklerini iyileştirilmesi için çalışmalar hız kazanmıştır. Literatürde 1Propanol'ün benzin katkı maddesi olarak kullanımı ile ilgili çok az sayıda çalışma olmasına rağmen optimizasyon çalışmasına rastlanmamıştır. $\mathrm{Bu}$ çalışmada motor devri ve \% 1-Propanol oranına bağlı olarak egzoz emisyon değerleri $\left(\mathrm{CO}, \mathrm{CO}_{2}, \mathrm{HC}, \mathrm{O}_{2}\right.$, ve NO) YYM ile optimize edilerek emisyonlar için ideal koşullar belirlenmiştir. Ayrıca YYM sayesinde test sayıları azaltılarak, herbir parametrenin tahmin fonksiyonları matematiksel olarak elde edilmiştir.

\section{Materyal ve Metot}

\subsection{Yakıt Karışımları ve Test Düzeneği}

Yakıt karışımları Sigma Aldrich tarafından tedarik edilen \%99.9 saflıkta 1-Propanolün hacimce \%5 (P5), \%10 (P10) ve \%15 (P15) oranında benzin ile karıştırılması ile elde edilmiştir. Ayrıca kıyas yakıtı olarak OPET'ten tedarik edilen 95 Oktan Benzin kullanılmıştır. Yakıt özellikleri tablo 1'de verilmiştir.

Tablo 1. Yakıt Özellikleri

\begin{tabular}{|c|c|c|}
\hline Özellik & Benzin & 1-Propanol \\
\hline Yoğunluk $(\mathrm{g} / \mathrm{ml})$ & 0,775 & 0,804 \\
\hline Parlama Noktası $\left({ }^{\circ} \mathrm{C}\right)$ & $<-40$ & 22 \\
\hline $\begin{array}{l}\text { Kendiliğinden Tutuşma } \\
\text { Sicaklığl }\left({ }^{\circ} \mathrm{C}\right)\end{array}$ & $>250$ & 372 \\
\hline Kaynama Noktası & $>32$ & $>97$ \\
\hline Oktan Sayısı & 95 & 98 \\
\hline Alt Isıl De ğer (kJ/kg) & 43430 & 30630 \\
\hline
\end{tabular}

Testler 1.2 TSI direkt enjeksiyonlu 4 zamanlı ve 4 silindir bir benzinli motor ile 1500,2500 ve $3500 \mathrm{~d} / \mathrm{dk}$ 'da $100 \mathrm{~kW}$ maksimum güç ve $750 \mathrm{Nm}$ maksimum tork değerleri sağlayabilen BT-190 FR hidrolik dinamometre kullanılarak kısmi yük altında gerçekleştirilmiştir. Test motorunun özellikleri tablo 2'de, test düzeneği ise şekil 1'de verilmiştir. Emisyon değerleri Bosch BEA 350 model egzoz emisyon cihazı ile ölçülmüştür.

Tablo 2. Test Motoru Özellikleri

\begin{tabular}{|l|c|}
\hline Özellik & Nitelik \\
\hline Model & 1.2 TSI, 4 zamanl, Direk Enj. \\
\hline Motor Hacmi & $1197 \mathrm{~cm} 3$ \\
\hline Silindir Saylsl & 4 \\
\hline Slkıştırma Oranı & $10: 1$ \\
\hline Silindir Çapı & $71 \mathrm{~mm}$ \\
\hline Strok & $75.6 \mathrm{~mm}$ \\
\hline Motor Gücü & $77 \mathrm{~kW}(5000 \mathrm{~d} / \mathrm{dk})$ \\
\hline Motor Torku & $175 \mathrm{Nm}(1550-4100 \mathrm{~d} / \mathrm{dk})$ \\
\hline Turbo Basıncl & $160 \mathrm{kPa}(3500 \mathrm{~d} / \mathrm{dk})$ \\
\hline Emisyon Standartı & Euro 5 \\
\hline Motor Kontrol Sistemi & Continental Simos 10 \\
\hline
\end{tabular}




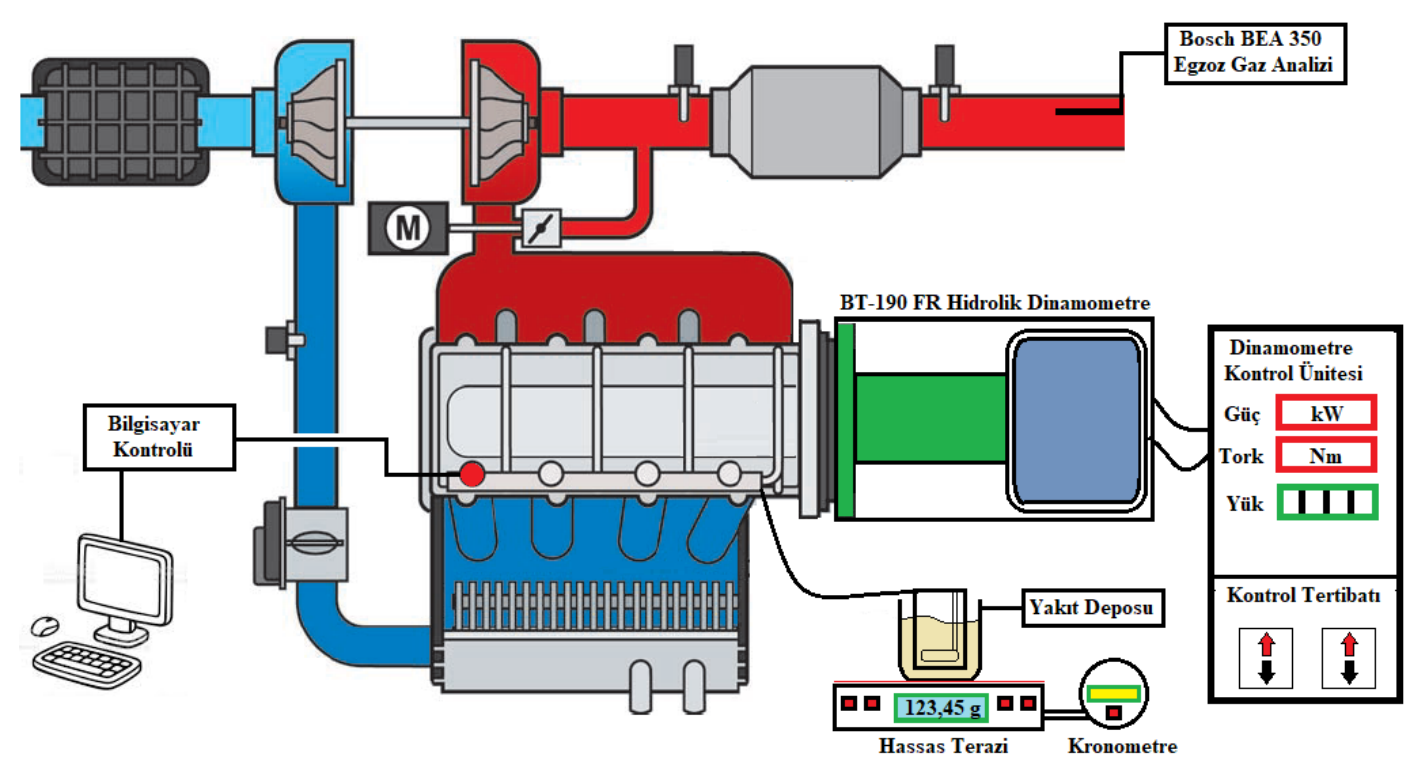

Şekil 1. Motor Test Düzeneği

\subsection{Yanıt Yüzey Metodolojisi}

YYM, test sayılarının azaltılması ve sonuçların optimizasyonu için giriş faktörlerinin yanıt değerleri üzerindeki etkisini istatistiksel ve matematiksel yöntemler kullanarak incelenmesini sağlayan bir deney tasarımı tekniğidir. Bu teknik ile giriş faktörlerinin yanıt değerleri üzerindeki etkileri matematiksel bir tahmin fonksiyonu ile ifade edilebilmektedir. Yanıt değeri, faktörlerin doğrusal bir fonksiyonu ile istatistiksel olarak anlamlı olacak şekilde modellenmişse, tahmin fonksiyonu birinci dereceden bir model olarak tanımlanmaktadır. Tahmin fonksiyonu, $\beta$ sabit katsayıyı, $\mathrm{k}$ giriş faktörü sayısını, $\in$ standart hatayı ve $X$ giriş değerini temsil etmek üzere denklem 1'de verildiği ifade edilmektedir (Anderson-Cook et al., 2009). Doğrusal olarak açıklanması mümkün olmayan fonksiyonlar ise $i$ doğrusal, $j$ polinomal katsayıyı temsil etmek üzere denklem 2'de verildiği gibi ifade edilmektedir(Montgomery, 2006).

$$
\begin{gathered}
y=\beta_{0}+\beta_{1} X_{1}+\beta_{2} X_{2}+\beta_{k} X_{k}+\epsilon \\
y=\beta_{0}+\sum_{i=1}^{k} \beta_{i} X_{i}+\sum_{i=1}^{k} \beta_{i i} X_{i}^{2}+\sum \sum_{i<j}^{k} \beta_{i j} X_{i} X_{j}+\epsilon
\end{gathered}
$$

$\mathrm{R}^{2}$ değeri determinasyon katsayısı olarak 0 ile 1 arasında tanımlanan bir istatistiksel parametredir ve 1'e ne kadar yakınsa yanıt değerleri giriş faktörleri ile o kadar iyi açıklanabilmektedir. $y_{i}$ yanıt değerinin gerçek değeri, $\hat{y}_{i}$ tahmini değeri olmak üzere $\mathrm{R}^{2}$ değeri denklem 3 te verildiği gibi hesaplanmaktadır(Bradley, 2007). Düzeltilmiş $R^{2}$ değeri, $R^{2}$ değerini etkileyen fakat istatistiksel olarak anlamsız olan gürültü verilerinin etkisini ortadan kaldırmak için kullanılır. $n$ hesaplamaya dahil edilen toplam veri sayısını ve $p$ ise bağımsız değişken sayısı olmak üzere denklem 4'te verilen bağıntı ile hesaplanmaktadır(Ostertagová, 2012). Ortalama Mutlak Hata (OMH), gerçek değer ile hesaplama sonucunda bulunan yaklaşık değer arasındaki farkı ifade eden mutlak hata değerinin, bütün test koşulları dahil edilerek ortalamasının alınması ile elde edilmektedir ve $\propto$, hata sayısını ve $\left|x_{i}-x\right|$ ise mutlak hatayı temsil etmek üzere denklem 5 te verilen bağıntı ile hesaplanmaktadır(Carley et al., 2004).

$$
\begin{gathered}
R^{2}=100\left(1-\frac{\sum_{i=1}^{n}\left(y_{i}-\hat{y}_{i}\right)^{2}}{\sum_{i=1}^{n}\left(y_{i}-\bar{y}_{i}\right)^{2}}\right) \% \\
R_{d}^{2}=100\left(1-\left(\frac{n-1}{n-p-1}\right) \frac{\sum_{i=1}^{n}\left(x_{i}-\hat{x}_{i}\right)^{2}}{\sum_{i=1}^{n}\left(x_{i}-\bar{x}_{i}\right)^{2}}\right) \% \\
O M H=\frac{1}{\propto} \sum_{i=1}^{\propto}\left|x_{i}-x\right|
\end{gathered}
$$

YYM kullanılarak yapılan deney tasarımlarında farklı teknikler kullanılarak optimizasyon yapılabilmektedir(Gökmen \& Bilban, 2020). 3SFT tekniği ile $\mathrm{k}$ ya bağlı olarak $3^{\mathrm{k}}$ adet test kombinasyonu oluşturulmuştur ve bu teknik giriş faktörlerinin en düşük, orta ve en yüksek seviyelerinde değerlendirme imkanı sağladığı için tercih edilmiştir. Bu çalışmanın giriş faktörleri ve seviyeleri tablo 3 'te gösterilmiştir aynı zamanda CO (\% hacim) , $\mathrm{CO}_{2}$ (\% hacim), $\mathrm{HC}$ (ppm), $\mathrm{NO}$ (ppm) ve $\mathrm{O}_{2}$ (\% hacim) emisyonları ise yanıt değerleri olarak belirlenmiştir.

Tablo 3. Giriş Faktörleri ve Seviyeleri

\begin{tabular}{|l|c|c|c|}
\hline Giriş Faktörleri & \multicolumn{3}{|c|}{ Seviyeler } \\
\hline 1-Propanol (\% hacim) & 5 & 10 & 15 \\
\hline Motor Devri (d/dk) & 1500 & 2500 & 3500 \\
\hline
\end{tabular}

Yanıt değerlerinin optimum noktalarının bulunabilmesi için tanımlanan arzu edilirlik (desirabilty, d) fonksiyonu, tahmin edilen yanıt değerinden faydalanarak bir integrasyon işlemine tabi tutulması sonucunda 0 ile 1 aralığında bir değer alması işlemidir. Optimize edilecek yanıt değerinin maksimize, minimize yada sabit bir değerde tutulması gerekliliği ölçüm sonuçları ile yapılan kıyaslamaların doğruluğu açısından çok önemlidir ve bu nedenle araştırmacılar tarafından YYM modeli oluşturulurken "yanıt hedefi" tanımlanmaktadır (Wagner, J. R., Mount, E. M., \& Giles, 2014). Bu çalışmanın hedefi egzoz emisyon değerlerinin azaltılması olduğu için tüm yanıt değerlerinin arzu edilirlik fonksiyonu denklem (11) ' de verilen minimizasyon formülü hesaplanmıştır. $\widehat{\boldsymbol{y}}$ tahmin edilen yanıt değeri, $\boldsymbol{m i n}$ kabul edilebilir 
en düşük ölçüm değer, $\boldsymbol{m a x}$ tanımlanan yanıt hedefine göre en uygun ölçüm değeridir. $\boldsymbol{f} \boldsymbol{t}$ ise fonksiyon eğrisellik üstelidir. Yanıt hedefinin minimizasyon olduğu yaklaşımlarda arzu edilirlik fonksiyonu değerinin 0 a en yakın olması gerekmektir (Saravanan et al., 2017).

$$
d(y)=\int_{0}^{1}\left(\frac{\hat{y}-\max }{\min -\max }\right)^{f t}, \quad \begin{gathered}
\hat{y}<\min \\
\min \leq \hat{y} \leq \max \\
\hat{y}>\max
\end{gathered}
$$

\section{Araştırma Sonuçları ve Tartışma}

Egzoz emisyon testleri gibi yanıt değerlerinin kendi aralarında içsel ilişkiye (interkorelasyon) sahip olduğu durumlarda giriş parametrelerinin herbir yanıt değeri üzerindeki etkisinin belirlenmesi için kullanılan varyans analizi (ANOVA), yanıt değişkenlerinin tekrarsız kombinasyonlarının regresyonu sonucunda giriş parametreleri ile ilişkilendirilmesini sağlamaktadır. ANOVA analizi, $\mathrm{R}^{2}, \mathrm{Rd}^{2}, \mathrm{~F}$ testi değeri (F-Değeri), olasılık değeri (P-Değeri) gibi faktörlerin yanı sıra faktörlerin üstel değerleri $\left(\mathrm{A}^{2}, \mathrm{~B}^{2}, \mathrm{~A}^{*} \mathrm{~B}\right)$ gibi istatistiksel faktörleri içermektedir. P-Değeri 0.05 'ten küçük olduğu durumlarda sonuç istatistiksel olarak önemlidir. Ayrıca F-Değerinin büyük olması ise istatistiksel olarak anlamlılığı artırmaktadır. Yanıt değerlerinin giriş değerleri ile açıklanabilirliğinin bir ölçüsü olan $\mathrm{R}^{2}$ değerleri tüm emisyonlar için \%98 üzerindedir, ayrıca 2 ve daha fazla giriş parametresinin olduğu durumlarda kıyaslama için daha önemli olan $\mathrm{Rd}^{2}$ ise $\mathrm{CO}, \mathrm{CO}_{2}, \mathrm{HC}, \mathrm{O}_{2}$, ve $\mathrm{NO}$ için sırasılyla \%96.30, $\% 98.73$, \%99.54, \%99.91 ve \%99.72 dir. Tablo 4'te yanıt parametreleri için ANOVA sonuçları verilmiştir.

YYM, geleneksel istatistiksel yaklaşımlardan farklı olarak bir test prosedürünün matematiksel fonksiyonunu elde etmek için kullanılmaktadır. Elde edilen fonksiyon bilinen ölçüm sonuçları ile kıyaslanarak tahmin performansı gözlemlenebilirken test prosedüründe yer almayan giriş değerleri için tahmin imkanı sağlamaktadır. $\mathrm{Bu}$ çalışmada $\mathrm{CO}, \mathrm{CO}_{2}, \mathrm{HC}, \mathrm{O}_{2}$, ve $\mathrm{NO}$ için giriş parametrelerine bağlı olarak elde edilen 2. dereceden fonksiyonlar motor devri d/dk (MD) ve 1-Propanol oran $\%$ hacim (AO) olmak üzere sirasiyla (6), (7), (8), (9) ve (10) numaralı denklemlerde verilmiştir. Tablo 5, yakıt karışımlarının test sonuçlarındaki emisyon ölçüm ve tahmin değerlerini karşılaştırmalı olarak vermektedir. \% Hata değeri, tahmin değerinin ölçüm değeri ile yüzdelik farkını göstermektedir. Eğer tahmin değeri ölçüm değerinden küçük ise "_" indisi büyük ise "+" indisi ile belirtilmiştir. Benzin kıyas yakıtı olduğu için tahmin sonuçları tabloda yer almamaktadır.

$$
\begin{aligned}
C O=-0,232153 & +0,000625833 * M D \\
& +0,0270917 * A O-(1,40833 E \\
& \left.-7 * M D^{2}\right)-\left(3,65 * 10^{-6} * M D\right. \\
& * A O)-\left(0,000473333 * A O^{2}\right) \\
C O_{2}=2,57083 & +0,00516667 * M D \\
& -0,138167 * A O-(5,9 E-7 \\
& \left.* M D^{2}\right)+0,000027 * M D * A O \\
& -0,002 * A O^{2}
\end{aligned}
$$

$$
\begin{aligned}
H C=76,9306 & +0,0096667 * M D-1,2 * A O \\
& -4,83 * 10^{-6} * M D^{2}+0,0002 \\
& * M D * A O+0,006667 * 1 \\
& -A O^{2} \\
O_{2}=22,4172- & 0,01205 * M D-0,2015 * A O \\
& +1,67 * 10^{-6} * M D^{2}+49 \\
& * 10^{-6} * M D * A O+0,0016667 \\
& * A O^{2} \\
& \\
N O=-990,958 & +1,9505 * M D-1,325 * A O \\
& -0,0002145 * M D^{\wedge} 2 \\
& -0,00315 * M D * A O-0,28 \\
& * A O^{\wedge} 2
\end{aligned}
$$

Test çalışmaları artan 1-Propanol miktarı ile orantılı bir şekilde $\mathrm{CO}_{2}, \mathrm{HC}, \mathrm{O}_{2}$ ve $\mathrm{NO}$ emisyonlarında azalma $\mathrm{CO}$ emisyonlarında ise artma olduğunu göstermektedir. $1500 \mathrm{~d} / \mathrm{dk}$ da yapılan testlerde, P15 karışımının $\mathrm{CO}_{2}, \mathrm{HC}, \mathrm{O}_{2}$ ve $\mathrm{NO}$ emisyonlar1 sirasiyla \%20.28, \%16.86, \%25.34 ve \%7.31 oranlarında azalırken CO emisyonu \%34,42 oranında artmıştır. $2500 \mathrm{~d} / \mathrm{dk}$ da yapılan testlerde ise $\mathrm{P} 15$ yakıtında $\mathrm{O}_{2}, \mathrm{CO}_{2}, \mathrm{HC}$ ve NO emisyonları sirasiyla $\% 27.03, \% 18.76, \% 12,85$ ve $\% 11,91$ oranlarında azalırken $\mathrm{CO}$ emisyonu \%10,46 oranında artmıştır. $3500 \mathrm{~d} / \mathrm{dk}$ da yapılan testlerde ise $\mathrm{CO}_{2}, \mathrm{HC}, \mathrm{O}_{2}$ ve $\mathrm{NO}$ emisyonları sirasıyla $\% 5.03, \% 16.36, \% 36.78$ ve $\% 8.31$ azalırken $\mathrm{CO}$ emisyonu \%31,88 artmıştır. Şekil 3’te grafikleri verilen YYM fonksiyonları kullanılarak yapılan hesaplamalar tüm ölçüm sonuçlarını \%90 üzerinde doğru tahmin etmiştir. En yüksek hata P5 ve P15 karışımlarının $3500 \mathrm{~d} / \mathrm{dk}$ daki $\mathrm{O}_{2}$ emisyonu değerinde sırasıyla \%8.24, \%6,16 olarak hesaplanmıştır ve bunlar haricindeki tüm tahmin hataları $\% 5$ ten düşüktür.

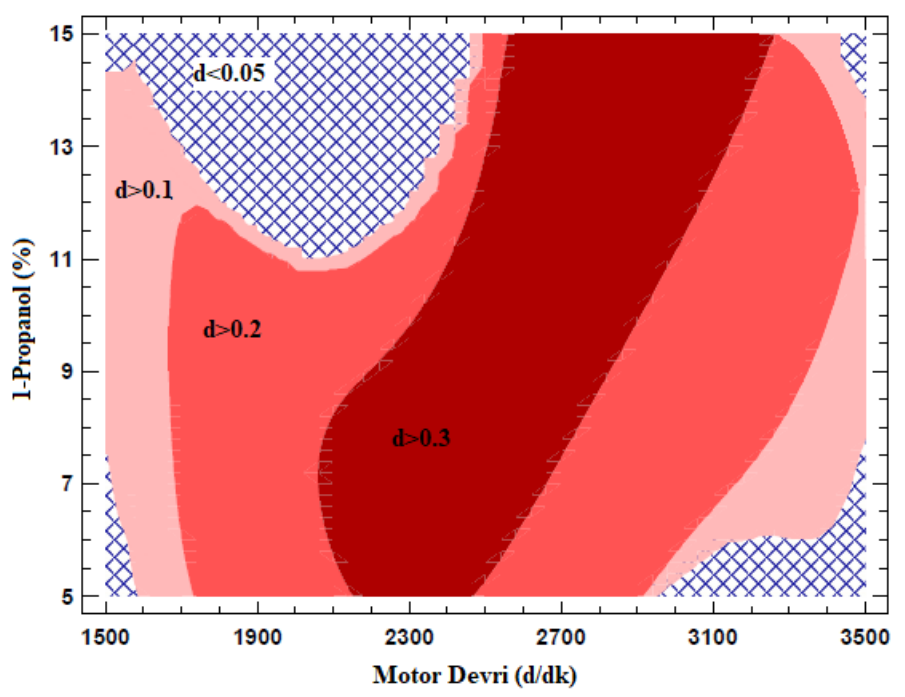

Şekil 2. Model Arzu Edilirlik Fonksiyonu Grafiği

Motor devri ve 1-Propanol oranına bağlı olarak YYM modelinin arzu edilirlik fonksiyonu grafiği şekil 3 te verilmiştir. Ayrıca her yanıt değeri için minimum ve optimum değerler arzu edilirlik fonksiyonuna bağlı olarak hesaplanmıştır. Model arzu edilirlik fonksiyonu grafiğinde taralı alanlar $(\mathrm{d}<0.05)$ en iyi optimum nokta tahminlerinin yapıldığı bölgeleri göstermektedir. Taralı alan haricinde kalan bölgeler için arzu edilirlik fonksiyonun değerleri artış göstermektedir bu nedenle o bölgelerdeki tahminler istatistiksel olarak güvenilir değildir. Optimum noktaların 
doğrulukları, giriş parametrelerine göre yapılan gerçek ölçümler ile aynı nokta için yapılan tahminlerin yüzdesel olarak yakınlığının yüzdelik olarak ifade edilmesi ile kontrol edilir ve YYM modelinin doğru çalıştığının bir ölçüsüdür. Bu çalışmada $\mathrm{CO}, \mathrm{CO}_{2}, \mathrm{HC}, \mathrm{O}_{2}$ ve $\mathrm{NO}$ emisyonları için optimum değerler, minimum ölçüm değerleri baz alınarak yapılan hesaplamaya göre $\% 98.58, \% 98.88, \% 99.03, \% 99.33$ ve $\% 98.51$ doğrulukta $\%$ $0.292, \% 7.07,45.55$ ppm, \%7.49 ve 1298.42 ppm olarak tahmin edilmiştir. Bütün yanıt değerleri için optimum değer tahminleri $\% 95$ üzerinde doğruluktadır.

Tablo 4. ANOVA Tablosu (A: Motor Devri (d/dk) B:1-Propanol (\%))

\begin{tabular}{|c|c|c|c|c|c|c|c|c|c|c|}
\hline \multirow{2}{*}{ Parametre } & \multicolumn{2}{|c|}{$C O$} & \multicolumn{2}{|c|}{$\mathrm{CO}_{2}$} & \multicolumn{2}{|c|}{$H C$} & \multicolumn{2}{|c|}{$\mathrm{O}_{2}$} & \multicolumn{2}{|c|}{ NO } \\
\hline & P-Değeri & F-Değeri & P-Dĕgeri & F-Değeri & P-Değeri & F-Değeri & P-Değeri & F-Değeri & P-Değeri & F-Değeri \\
\hline$A$ & 0,0015 & 128,89 & 0,0002 & 586,53 & 0,0000 & 1582,03 & 0,0000 & 8437,43 & 0,0000 & 2868,96 \\
\hline$B$ & 0,0246 & 17,66 & 0,0125 & 29,04 & 0,0029 & 81,28 & 0,0074 & 42,25 & 0,0184 & 21,92 \\
\hline$A^{2}$ & 0,0040 & 64,62 & 0,0451 & 11,01 & 0,0030 & 78,84 & 0,0001 & 750,38 & 0,0043 & 61,40 \\
\hline$A * B$ & 0,2371 & 2,17 & 0,3617 & 1,15 & 0,0805 & 6,75 & 0,0107 & 32,43 & 0,4754 & 0,66 \\
\hline$B^{2}$ & 0,5478 & 0,46 & 0,7969 & 0,08 & 0,7795 & 0,09 & 0,5426 & 0,47 & 0,8147 & 0,07 \\
\hline$\overline{R^{2}}$ & \multicolumn{2}{|l|}{0,9861} & \multicolumn{2}{|l|}{0,9952} & \multicolumn{2}{|l|}{0,9982} & \multicolumn{2}{|l|}{0,9996} & \multicolumn{2}{|l|}{0,9989} \\
\hline$R d^{2}$ & \multicolumn{2}{|l|}{0,9630} & \multicolumn{2}{|l|}{0,9873} & \multicolumn{2}{|l|}{0,9954} & \multicolumn{2}{|l|}{0,9991} & \multicolumn{2}{|l|}{0,9972} \\
\hline$\overline{O M H}$ & \multicolumn{2}{|l|}{0,0120} & \multicolumn{2}{|l|}{0,1200} & \multicolumn{2}{|l|}{0,3950} & \multicolumn{2}{|l|}{0,0420} & \multicolumn{2}{|l|}{18,0700} \\
\hline
\end{tabular}
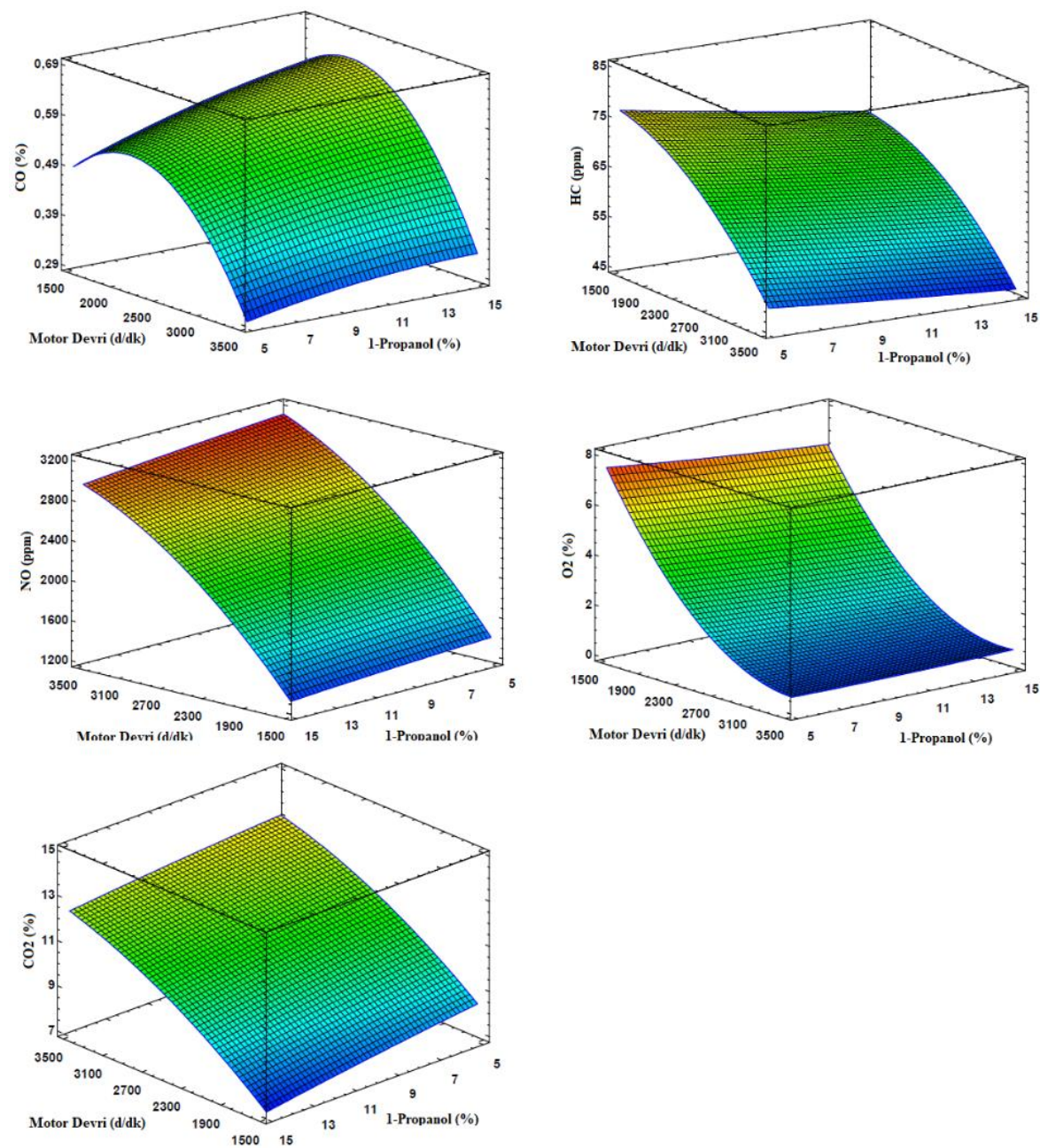

Şekil 3. Tüm Emisyon Değerleri İçin Yanıt Yüzey Grafikleri 
Tablo 5. Test Sonuçları ve YYM Tahminleri

\begin{tabular}{|c|c|c|c|c|c|c|c|c|c|c|c|c|c|c|c|c|}
\hline \multirow{2}{*}{$\begin{array}{c}\text { Motor Hizl } \\
\quad(d / d k)\end{array}$} & \multirow{2}{*}{ Yakıt } & \multicolumn{3}{|c|}{$\begin{array}{c}\text { CO } \\
(\% \text { Hacim })\end{array}$} & \multicolumn{3}{|c|}{$\begin{array}{c}\mathrm{CO}_{2} \\
(\% \text { Hacim })\end{array}$} & \multicolumn{3}{|c|}{$\begin{array}{c}\text { HC } \\
(\text { ppm })\end{array}$} & \multicolumn{3}{|c|}{$\begin{array}{c}\mathrm{O}_{2} \\
(\% \text { Hacim })\end{array}$} & \multicolumn{3}{|c|}{$\begin{array}{c}N O \\
(\text { ppm })\end{array}$} \\
\hline & & Ölçüm & Tahmin & \% Hata & Ölçüm & Tahmin & \% Hata & Ölçüm & Tahmin & \% Hata & Ölçüm & Tahmin & $\begin{array}{c}\% \\
\text { Hata }\end{array}$ & Ölçüm & Tahmin & $\begin{array}{c}\% \\
\text { Hata }\end{array}$ \\
\hline \multirow{4}{*}{1500} & Benzin & 0,459 & & & 8,97 & & & 83 & & & 8,72 & & & 1422 & & \\
\hline & $P 5$ & 0,497 & 0,486 & $-2,22$ & 8,29 & 8,455 & $\begin{array}{r}+1,99 \\
\end{array}$ & 76 & 76,222 & $\begin{array}{r}+0,29 \\
\end{array}$ & 7,54 & 7,494 & $-0,61$ & 1396 & 1414,92 & $\begin{array}{r}+1,36 \\
\end{array}$ \\
\hline & $P 10$ & 0,538 & 0,559 & $\begin{array}{r}+3,82 \\
\end{array}$ & 7,91 & 7,817 & $-1,18$ & 72 & 72,222 & $+0,31$ & 6,97 & 6,979 & $+0,13$ & 1363 & 1363,67 & $\begin{array}{r}+0,05 \\
\end{array}$ \\
\hline & $P 15$ & 0,617 & 0,607 & $-1,54$ & 7,15 & 7,078 & $-1,00$ & 69 & 68,556 & $-0,64$ & 6,51 & 6,547 & $\begin{array}{r}+0,57 \\
\end{array}$ & 1318 & 1298,42 & $-1,49$ \\
\hline \multirow{4}{*}{2500} & Benzin & 0,554 & & & 12,42 & & & 70 & & & 2,70 & & & 2619 & & \\
\hline & $P 5$ & 0,515 & 0,530 & $+2,96$ & 11,67 & 11,397 & $-2,34$ & 68 & 67,556 & $-0,65$ & 2,26 & 2,356 & $+4,23$ & 2532 & 2491,67 & $-1,59$ \\
\hline & $P 10$ & 0,612 & 0,615 & $\begin{array}{r}+0,53 \\
\end{array}$ & 10,82 & 10,893 & $\begin{array}{r}+0,68 \\
\end{array}$ & 65 & 64,556 & $-0,68$ & 2,11 & 2,086 & $-1,16$ & 2421 & 2424,67 & $\begin{array}{r}+0,15 \\
\end{array}$ \\
\hline & $P 15$ & 0,603 & 0,585 & $-3,06$ & 10,09 & 10,290 & $\begin{array}{r}+1,98 \\
\end{array}$ & 61 & 61,889 & $\begin{array}{r}+1,46 \\
\end{array}$ & 1,97 & 1,899 & $-3,61$ & 2307 & 2343,67 & $\begin{array}{r}+1,59 \\
\end{array}$ \\
\hline \multirow{4}{*}{3500} & Benzin & 0,261 & & & 13,11 & & & 55 & & & 0,87 & & & 3247 & & \\
\hline & $P 5$ & 0,297 & 0,293 & $-1,41$ & 13,05 & 13,158 & $+0,83$ & 49 & 49,222 & $+0,45$ & 0,60 & 0,551 & $-8,24$ & 3118 & 3139,42 & $\begin{array}{r}+0,69 \\
\end{array}$ \\
\hline & $P 10$ & 0,322 & 0,329 & $+2,14$ & 12,77 & 12,790 & $+0,16$ & 47 & 47,222 & $+0,47$ & 0,51 & 0,526 & $+3,05$ & 3061 & 3056,67 & $-0,14$ \\
\hline & $P 15$ & 0,344 & 0,341 & $-0,78$ & 12,45 & 12,322 & $-1,03$ & 46 & 45,556 & $-0,97$ & 0,55 & 0,584 & $+6,16$ & 2977 & 2959,92 & $-0,57$ \\
\hline
\end{tabular}




\section{Sonuç}

Bu çalışmada, 1197 (cc), turboşarj donanımlarına sahip, direk enjeksiyonlu benzinli bir motorda farkl1 oranlarda $(\% 5, \% 10$, \%15) 1-Propanol katkılı yakıtların farklı motor devirlerinde $(1500,2500,3500 \mathrm{~d} / \mathrm{dk})$ ve kısmi yük koşullarında emisyon değerlerine olan etkisi deneysel ve istatistiksel olarak incelenmiştir. Deney tasarımları için YYM/3SFT teknikleri kullanılmıştır. Motor devri (d/dk) ile 1-Propanol (\%) oranları giriş parametreleri emisyon değerleri ise çıkış parametreleri olarak belirlenmiştir. Giriş parametrelerinin her 3 seviyesi için toplam 9 adet test yapılmış ve bu testler \%100 benzin ile kıyaslanmıştır. Yapılan çalışma neticesinde 1-Propanol katkılı yakıt karışımlarında $\mathrm{CO}_{2}, \mathrm{HC}, \mathrm{O}_{2}, \mathrm{NO}$ emisyonlarının tüm motor devirlerinde azaldığı görülmüştür fakat $\mathrm{CO}$ emisyonları artış göstermiştir. Benzin değerlerine kıyasla en yüksek artış $1500 \mathrm{~d} / \mathrm{dk}$ motor hızında P15 karışımında \%34. 42görülürken en düşük artış ise aynı yakıt karışımı için $2500 \mathrm{~d} / \mathrm{dk}$ motor hızında \%10.46 olarak gerçekleşmiştir. 1-Propanol'ün benzine kıyasla daha düşük alt 1sıl değere sahip olması nedeni ile yanma performansına olumsuz etki etmektedir, ayrica kimyasal yapısında bulunan 3 adet metil grubu nedeni ile yakıtın karbon sayısını artırarak birim hava başına yakıtın daha fazla karbon içermesine neden olmaktadır ve bu nedenle CO emisyonları artmaktadır. CO emisyonları $2500 \mathrm{~d} / \mathrm{dk}$ motor devrine kadar artış göstermesine rağmen $2500 \mathrm{~d} / \mathrm{dk}$ ve üzerindeki devirlerde azalma eğilimine girmiştir. Bütün emisyon değerleri için giriş parametrelerine bağlı olarak matematiksel fonksiyonlar elde edilmiş ve bu modeller yanıt yüzey grafikleri ile açıklanmıştır. YYM tahmin fonksiyonları gerçek ölçüm sonuçları ile doğrulanmıştır ve bütün yanıt değeri fonksiyonları istatistiksel olarak önemlidir. Optimum yanıt değerleri arzu edilirlik (desirabilty) fonksiyonları kullanılarak doğrulanmış ve bütün modelin en iyi tahmin aralıkları giriş parametrelerine bağlı olarak belirlenmiştir. Yapılan çalışma neticesinde model arzu edilirlik fonksiyonu grafiği ve optimum değerler göz önüne alınarak 1-Propanol karışımlarının düşük motor devirleri için yüksek oranlarda ya da yüksek motor devirlerinde düşük oranlarda kullanım için uygun olduğu görülmektedir. Yanıt yüzey grafikleri göz önüne alınarak yüksek 1-Propanol oranı ve yüksek motor devrindeki kullanımların sadece HC emisyonu üzerinde doğrudan etkisi olduğu görülmektedir. $\mathrm{O}_{2}$ emisyonları motor devri ile doğru orantılı bir şekilde azalmıştır. $\mathrm{NO}$ ve $\mathrm{CO}_{2}$ emisyonları için en düşük değerler $1500 \mathrm{~d} / \mathrm{dk}$ ve P15 yakıtında elde edilmiştir. Ayrıca, alternatif yakıt testlerinde farklı parametrelerin egzoz emisyon değerleri üzerindeki etkilerinin incelenmesi için YYM kullanılması, daha az test gerekliliği nedeni ile çalışmanın daha düşük maliyet ile gerçekleşmesini sağlamaktadır.

\section{Kaynakça}

Abdalla, A. N., Tao, H., Bagaber, S. A., Ali, O. M., Kamil, M., Ma, X., \& Awad, O. I. (2019). Prediction of emissions and performance of a gasoline engine running with fusel oilgasoline blends using response surface methodology. Fuel, 253(April),

$1-14$ https://doi.org/10.1016/j.fuel.2019.04.085

Acaroğlu, M., Aydoğan, H., \& Özçelik, A. E. (2018). Yakıtlar ve Yanma. Nobel Akademi Yayıncilık.

Anderson-Cook, C. M., Borror, C. M., \& Montgomery, D. C.
(2009). Rejoinder for "Response surface design evaluation and comparison." Journal of Statistical Planning and Inference, $139(2)$, 671-674. https://doi.org/10.1016/j.jspi.2008.04.009

Bote, M. A., Naik, V. R., \& Jagdeeshgouda, K. B. (2020). Optimization of spark ignition engine adopting Taguchi access and response surface methodology. Fuel, 280(May), 118530. https://doi.org/10.1016/j.fuel.2020.118530

Bradley, N. (2007). The Response Surface Methodology [Indiana University of South Bend]. https://doi.org/10.1007/978-3662-44324-8 1998

Carley, K. M., Kamneva, N. Y., \& Reminga, J. (2004). Response surface methodology, CASOS Technical Report. https://doi.org/10.1002/wics.73

Draper, N. R. (1992). Introduction to Box and Wilson (1951) On the Experimental Attainment of Optimum Conditions. 1951, 267-269. https://doi.org/10.1007/978-1-4612-4380-9_22

Gawale, G. R., \& Naga Srinivasulu, G. (2020). Experimental investigation of propanol dual fuel HCCI engine performance: Optimization of propanol mass flow rate, impact of butanol blends (B10/B20/B30) as fuel substitute for diesel. Fuel, 279(March), 118535. https://doi.org/10.1016/j.fuel.2020.118535

Gökmen, M. S., \& Bilban, M. (2020). Optimization of Internal Combustion Engine Tests with Response Surface Methodology: A Review. Renewable Energy Sources Energy Policy and Energy Management, 1(2), 34-41.

Jarmon, G., \& Anderson, P. (2005). Special Gasoline Blends (No. 05-421; GAO, Issue June).

Li, W., Zhang, Y., Mei, B., Li, Y., Cao, C., Zou, J., Yang, J., \& Cheng, Z. (2019). Experimental and kinetic modeling study of n-propanol and i-propanol combustion: Flow reactor pyrolysis and laminar flame propagation. Combustion and Flame, 207, 171-185. https://doi.org/10.1016/j.combustflame.2019.05.040

Liu, X., Wang, H., Zheng, Z., Liu, J., Reitz, R. D., \& Yao, M. (2016). Development of a combined reduced primary reference fuel-alcohols (methanol/ethanol/propanols/butanols/n-pentanol) mechanism for engine applications. Energy, 114, 542-558. https://doi.org/10.1016/j.energy.2016.08.001

Montgomery, D. C. (2006). Design and Analysis of Experiments. In Technometrics (Vol. 48, Issue 1). https://doi.org/10.1198/tech.2006.s372

Mourad, M., \& Mahmoud, K. R. M. (2018). Performance investigation of passenger vehicle fueled by propanol/gasoline blend according to a city driving cycle. Energy, 149, 741-749. https://doi.org/10.1016/j.energy.2018.02.099

Ostertagová, E. (2012). Modelling using polynomial regression. Procedia Engineering, 48(December 2012), 500-506. https://doi.org/10.1016/j.proeng.2012.09.545

Papa, A. J. (2000). Propanols. Ullmann's Encyclopedia of Industrial Chemistry. https://doi.org/10.1002/14356007.a22_173 
Qian, Y., Guo, J., Zhang, Y., Tao, W., \& Lu, X. (2018). Combustion and emission behavior of N-propanol as partially alternative fuel in a direct injection spark ignition engine. Applied Thermal Engineering, 144, 126-136. https://doi.org/10.1016/j.applthermaleng.2018.08.044

Reif, K. (2015). Gasoline Engine Management Systems and Components. In Springer Vieweg. Springer Vieweg.

Saravanan, S., Rajesh Kumar, B., Varadharajan, A., Rana, D., Sethuramasamyraja, B., \& Lakshmi Narayana rao, G. (2017). Optimization of DI diesel engine parameters fueled with iso-butanol/diesel blends - Response surface methodology approach. Fuel, 203, 658-670. https://doi.org/10.1016/j.fuel.2017.04.083

Srivastava, S. P., \& Hancsók, J. (2014). Fuels and Fuel-Additives. In John Wiley \& Sons. John Wiley \& Sons.

Wagner, J. R., Mount, E. M., \& Giles, H. F. (2014). Design of Factorial Experiments. Extrusion, 291-308. https://doi.org/10.1016/B978-1-4377-3481-2.00025-9

Yusri, I. M., Mamat, R., Azmi, W. H., Omar, A. I., Obed, M. A., \& Shaiful, A. I. M. (2017). Application of response surface methodology in optimization of performance and exhaust emissions of secondary butyl alcohol-gasoline blends in SI engine. Energy Conversion and Management, 133(2017), 178-195. https://doi.org/10.1016/j.enconman.2016.12.001 